\title{
Sequential appearance of four clinical delayed drug hypersensitivity in the same patient
}

\author{
Leena Chularojanamontri ${ }^{1}$, Papapit Tuchinda ${ }^{1}$, Yuttana Srinoulprasert ${ }^{2}$, \\ Kanokvalai Kulthanan ${ }^{3}$, Werner J. Pichler ${ }^{2,3 *}$
}

\begin{abstract}
${ }^{1}$ Department of Dermatology, Faculty of Medicine Siriraj Hospital, Mahidol University, Bangkok, Thailand

${ }^{2}$ Department of Immunology, Faculty of Medicine Siriraj Hospital, Mahidol University, Bangkok, Thailand

${ }^{3}$ ADR-AC GmbH, Holligenstr 91, 3008 Bern Switzerland
\end{abstract}

Received: 07 September 2016 Accepted: 12 October 2016

\section{*Correspondence to: \\ Dr. Werner J. Pichler, \\ Email: werner.pichler@adr- ac.ch}

Copyright: (C) the author(s), publisher and licensee Medip Academy. This is an openaccess article distributed under the terms of the Creative Commons Attribution NonCommercial License, which permits unrestricted noncommercial use, distribution, and reproduction in any medium, provided the original work is properly cited.

\begin{abstract}
This patient had a two-month history of four clinical manifestations of drug hypersensitivity reactions (DHR): maculo papular eruption, Drug Reaction with Eosinophilia and Systemic Symptoms (DRESS), acute generalized exanthematous pustulosis (AGEP) and toxic epidermal necrolysis (TEN). The eliciting drugs were rifampicin, possibly gabapentin, levofloxacin, meropenam and/or colistin. Thus, the patient might develop a multiple drug hypersensitivity syndrome. The TEN-like lesion appeared after stopping drugs for two days. A different manifestation of DHR in dependence of drug use suggests that the distinct manifestations of DHRs are due to the stimulation of $\mathrm{T}$ cells with distinct functions. The simultaneous appearance of AGEP and DRESS symptoms might be due to the simultaneous stimulation of two (or more) different $\mathrm{T}$ cell subsets, which are functionally dominant. Lastly, the appearance and further propagation of symptoms after therapy-stop is a common but somewhat neglected problem in DHR, which raises questions regarding the cause of persisting $\mathrm{T}$ cell activation.
\end{abstract}

Keywords: AGEP, Drug hypersensitivity reactions, DRESS, Mechanisms, Sequential appearance

\section{INTRODUCTION}

The appearance of four distinct clinical symptoms of delayed appearing drug hypersensitivity reaction (DHR) in one patient is unusual and has not yet been described. The time-limited and changing drug exposure suggests that the patient reacted to various drugs and might develop a multiple drug hypersensitivity (MDH) syndrome during treatment. In this syndrome structurally unrelated drugs elicit immune-mediated reactions, which can be clinically similar, or different to the first manifestation of DHR. ${ }^{1}$ In this patient maculo papular rash (MPE), drug reaction with eosinophilia and systemic symptoms (DRESS), acute generalized exanthematous pustulosis (AGEP) and toxic epidermal necrolysis (TEN) developed. Regretfully, the rapid and fatal clinical course made it impossible to investigate $\mathrm{MDH}$ by skin or in vitro tests.

\section{CASE REPORT}

A 63-year-old woman with obesity was admitted to Siriraj hospital due to periprosthetic joint infection of the left knee. She was already under gabapentin $(300 \mathrm{mg} / \mathrm{d})$ for 30 days. Rifampicin (450 mg/d) and levofloxacin $(750 \mathrm{mg} / \mathrm{d})$ were started for 4 days and 2 days, respectively to treat as methicillin-resistant Staphylococcus aureus joint infection. ${ }^{2}$ Then, she developed a pruritic MPE on the trunk and extremities without mucosal involvement. The suspected drug 
(rifampicin) was discontinued resulting in resolution of the rash within two days. Seventeen days later, rifampicin had to be restarted due to uncontrolled periprosthetic joint infection (Figure 1). After four days she developed fever $\left(40^{\circ} \mathrm{C}\right)$, jaundice, facial edema, and generalized erythematous rash without mucosal involvement (Figure 2a). Laboratory investigations revealed leucocytosis $(12,500 / \mu \mathrm{L}), \quad$ eosinophilia $(1002 / \mu \mathrm{L}), \quad$ atypical lymphocytes $(625 / \mu \mathrm{L})$, and elevated liver enzymes (Figure 1). Blood and urine culture and serology for antinuclear antibody, Mycoplasma pneumoniae, Epstein-Barr virus, hepatitis $\mathrm{A}, \mathrm{B}$ and $\mathrm{C}$ virus were negative. DRESS was diagnosed. Rifampicin, levofloxacin, and gabapentin that had been started for 4, 23, and 53 days, respectively were discontinued. She experienced a significant improvement in her general conditions and her temperature returned to normal. Aspartate transaminase (AST) and alanine aminotransferase (ALT) values gradually decreased from 485 to 282 IU/L and from 726 to $281 \mathrm{IU} / \mathrm{L}$ within six days. However, her serum creatinine increased from normal level $(0.63 \mathrm{mg} / \mathrm{dl})$ to $1.61 \mathrm{mg} / \mathrm{dl}$.

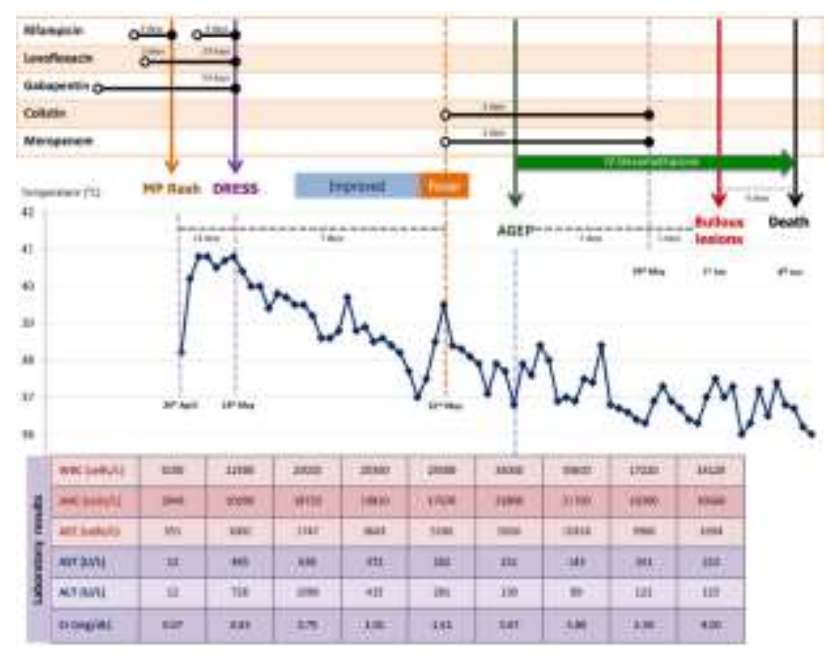

Abbreviation: $\mathrm{WBC}=$ white blood cell count, $\mathrm{ANC}=$ absolute neutrophil count, $\mathrm{AEC}=$ absolute eosinophil count, $\mathrm{AST}=$ aspartate transaminase, $\mathrm{ALT}=$ alanine aminotransferase, $\mathrm{Cr}=$ creatinine.

\section{Figure 1: Clinical course of the patient during hospital admission.}

On day $7^{\text {th }}$ after drug discontinuation, she developed high temperature $\left(39.5^{\circ} \mathrm{C}\right)$. A search for an infectious agent was negative and she was started on colistin $(160 \mathrm{mg} / \mathrm{d})$ and meropenam $(2 \mathrm{~g} / \mathrm{d})$. After two days, non-follicular pustules on erythematous skin (AGEP) appeared on her trunk and extremities without mucous membrane involvement (Figure 2b). Peripheral blood neutrophils and eosinophils rose to $23,800 / \mu \mathrm{L}$ and $5,950 / \mu \mathrm{L}$, respectively and serum creatinine to $3.67 \mathrm{mg} / \mathrm{dl}$. Multiple drug hypersensitivity (MDH) and flare-up reactions were considered. Intravenous dexamethasone was initiated. Colistin and meropenam were continued for five days, but were then stopped as her condition significantly deteriorated. After two days of drug discontinuation, large tense bullae and peeling of the skin developed on her trunk and extremities (40\% of body surface area, without mucosal involvement) (Figure 2c). The patient passed away within six days in spite of drug discontinuation and intensive care.
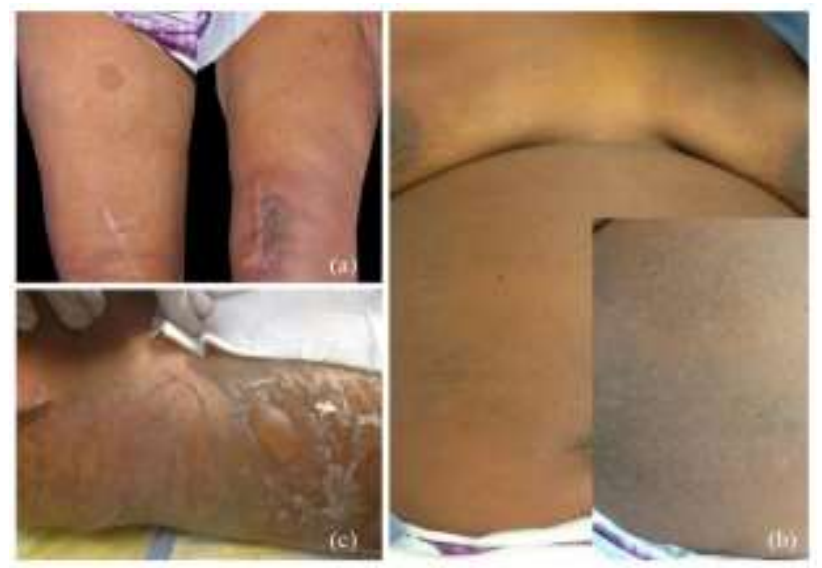

Figure 2: (a) Maculo papular rash, (b) Non-follicular pustules on erythematous skin, (c) Large tense bullae.

\section{DISCUSSION}

Severe cutaneous adverse reactions to drugs (SCARs) include DRESS, AGEP, Stevens-Johnson syndrome (SJS), and TEN. ${ }^{3}$ The diagnosis is sometime difficult due to overlap in their clinical presentations. Overlapping SCARs are defined as fulfilling the criteria for definite or probable diagnosis of at least 2 severe adverse drug reactions (DRESS, AGEP, and SJS-TEN). According to European registry of SCAR (RigiSCAR), our patients had definite diagnosis criteria of DRESS which included fever $>38.5{ }^{\circ} \mathrm{C}$, eosinophilia, presence of atypical lymphocytes, maculo papular rash involved $>50 \%$ body surface area, negative for other possible causes. ${ }^{4}$ The common causative drugs for DRESS were aromatic anticonvulsants, followed by allopurinol, sulphonamides, and other antibiotics. ${ }^{3-5}$ Rifampicin and levofloxacin have been reported to be causative drugs. ${ }^{5}$ Thus, all of the suspected drugs were discontinued resulting in a significant clinical improvement of our patient.

Our patient developed non-follicular pustules on erythematous base (AGEP-like eruptions) after starting meropenam ( $\beta$-lactam) and colistin. According to RegiSCAR, the diagnosis of AGEP was probable due to acute onset of typical skin rash, distribution, no mucosal involvement, neutrophilia $>7$ cells $/ \mu \mathrm{L} .{ }^{4}$ A flare-up reaction, characterized by rapid appearance of symptoms (1-2 days) after treatment with a potential allergic substance in a patient who already shows signs of ongoing drug hypersensitivity is also unlikely, as the patient had an intermittent improvement and as most cases of flare up reactions usually present with an enhancement of the same pre-existing skin lesions (mainly exanthemas). ${ }^{6}$ Pustular eruptions or AGEP-like eruptions may appear in 
relatively few cases of DRESS, but normally at the start and not after remission of DRESS. ${ }^{7}$ In severe cases of DRESS and AGEP, large tense bullae and TEN-like lesions can develop which are sometimes very difficult to distinguish among DRESS, AGEP and SJS-TEN. Our patients developed large tense bullae and TEN-like lesions after the DRESS and AGEP related skin symptoms had already disappeared.

We consider this case as instructive for various aspects of drug hypersensitivity reaction (DHR):

a) The discrimination of different cutaneous manifestations of DHR is important for judging the severity of the DHR and for possible test procedures. It is reflecting the predominant activation of functionally dominant $\mathrm{T}$ cells coordinating a certain inflammatory reaction and served as model for the revised sub-classification of Gell and Coombs type 4 into type 4 a-d: ${ }^{8}$ e.g. TEN can be seen as paradigm for a dominant cytotoxic cellular immune response (type 4c), where cytotoxic CD8+ T cells kill keratinocyte via granzyme $\mathrm{B} /$ perforin/granulysin and FasL. ${ }^{8,9}$ The strong eosinophilia in many DHR, particularly in DRESS, can be connected to massively IL-5 producing T cells (type $4 \mathrm{~b}$ ), and the appearance of neutrophils in the skin links AGEP to high IL-8/GM-CSF production. ${ }^{10}$ The sequential appearance of four different clinical manifestations of DHR in the case presented can thus be seen as an (over) activation of a particular $\mathrm{T}$ cell subset stimulated by some of the drugs applied.

b) On the other hand, each of the cutaneous symptoms described is reflecting an inflammatory reaction, which is the result of complex immune stimulation and cannot be reduced to a single (albeit dominant) $\mathrm{T}$ cell function alone. e.g. the clinical picture of AGEP is linked to predominant activation of IL-8/GM-CSF secreting $\mathrm{T}$ cells, but cytotoxic $\mathrm{T}$ cells are also involved and necessary. ${ }^{11}$ IL-5 secreting $\mathrm{T}$ cells are decisive for the eosinophilia of DRESS, but the simultaneous hepatitis is linked to cytotoxic $\mathrm{T}$ cells. $^{12,13}$ This complexity is mirrored in the appearance of overlap syndromes, where two $\mathrm{T}$ cell functions dominate the clinical picture together. Such an overlap syndrome occurred also in the patient described, as her AGEP like skin reaction occurred together with signs of a massive eosinophilia (due to activation of IL-5 secreting T cells) and signs of liver damage (activation of cytotoxic $\mathrm{T}$ cells), both typical for DRESS. ${ }^{12,13}$

c) The last DHR symptom was a bullous skin reaction with massive keratinocyte detachment as seen in TEN. It appeared after drug therapy has already been stopped for two days, and extended further in the next days. This is a not uncommon situation in DHR, and is known to occur e.g. in amoxicillin induced MPE, where symptoms may appear on day $11^{\text {th }}$ or $12^{\text {th }}, 1-2$ days after a 10 days of treatment. How can one explain the DHR symptoms after drug elimination?
One possibility is renal insufficiency, as the kidney was already damaged (creatinine $>3 \mathrm{mg} / \mathrm{dl}$ ), and colistin itself is also a potential kidney damaging drug. On the other hand, the presence of the drug may only be needed for the start of $\mathrm{T}$ cell activation, but not for effector mechanism leading to symptoms. The already drug induced $\mathrm{T}$ cells keep on to be activated in the tissue in absence of the drug as the drug stimulated an auto or allo-immune mechanism, which persists for a while in the absence of drug. ${ }^{14}$

d) This patient developed sequentially four distinct clinical manifestations to different drugs - why didn`t she react to the different drugs with a similar reaction (e.g. exanthema only). The involved drugs are not linked to a certain skin reaction only, and are also not described to cause DHR upon a certain genetic background (e.g. a certain HLA-allele). Thus, it is likely that in this patient the type of drug, the rather high doses applied and the duration of treatment were decisive for the clinical pictures and differing manifestations of DHR seen in our patient.

\section{CONCLUSION}

In conclusion, we report a case of DHR presenting with clearly discernible clinical manifestations, namely MPE, DRESS, AGEP and TEN. The AGEP and DRESS symptoms were overlapping. The case supports the clinical discrimination of DHR phenotypes and the utility of the revised Gell and Coombs sub-classification (type 4a-d), but also points to some open questions of DHR, namely overlap syndromes and appearance of symptoms after drug treatment was stopped.

\section{ACKNOWLEDGEMENT}

We would like to thank you Dr. Thanisorn Sukakul for his support.

\section{Funding: No funding sources \\ Conflict of interest: None declared \\ Ethical approval: Not required}

\section{REFERENCES}

1. Daubner B, Groux-Keller M, Hausmann OV, Kawabata T, Naisbitt DJ, Park BK, et al. Multiple drug hypersensitivity: normal Treg cell function but enhanced in vivo activation of drug-specific $\mathrm{T}$ cells. Allergy. 2012;67:58-66.

2. Liu C, Bayer A, Cosgrove SE, Daum RS, Fridkin SK, Gorwitz RJ, et al. Clinical Practice Guidelines by the Infectious Diseases Society of America for the Treatment of Methicillin Resistant Staphylococcus aureus Infections in Adults and Children. Clin Infect Dis. 2011;52:e18-55.

3. Bouvresse S, Valeyrie-Allanore L, Ortonne $\mathrm{N}$, Konstantinou MP, Kardaun SH, Bagot M, et al. Toxic epidermal necrolysis, DRESS, AGEP: do overlap cases exist? Orphanet J Rare Dis. 2012;25:7. 
4. Kardaun SH, Sekula P, Valeyrie-Allanore L, Liss Y, Chu CY, Creamer D, et al. Drug reaction with eosinophilia and systemic symptoms (DRESS): an original multisystem adverse drug reaction. Results from the prospective RegiSCAR study. $\mathrm{Br} \mathrm{J}$ Dermatol. 2013;169:1071-80.

5. Cacoub P, Musette P, Descamps V, Meyer O, Speirs C, Finzi L, et al. The DRESS syndrome: a literature review. Am J Med. 2011;124:588-97.

6. Pichler WJ, Daubner B, Kawabata T. Drug hypersensitivity: flare-up reactions, cross-reactivity and multiple drug hypersensitivity. J Dermatol. 2011;38:216-21.

7. Matsuda H, Saito K, Takayanagi Y, Okazaki T, Kashima K, Ishikawa K, et al. Pustular-type druginduced hypersensitivity syndrome/drug reaction with eosinophilia and systemic symptoms due to carbamazepine with systemic muscle involvement. J Dermatol. 2013;40:118-22.

8. Pichler WJ. Delayed drug hypersensitivity reactions. Ann Intern Med. 2003;139:683-93.

9. Chung WH, Hung SI, Yang JY, Su SC, Huang SP, Wei CY, et al. Granulysin is a key mediator for disseminated keratinocyte death in Stevens-Johnson syndrome and toxic epidermal necrolysis. Nat Med. 2008;14:1343-50.

10. Britschgi M, Steiner UC, Schmid S, Depta JP, Senti $\mathrm{G}$, Bircher $\mathrm{A}$, et al. $\mathrm{T}$ cell involvement in drug induced acute generalized exanthematous pustulosis. J Clin Investig. 2001;107:1433-41.

11. Schmid S, Kuechler PC, Britschgi M, Steiner UC, Yawalkar N, Limat A, et al. Acute generalized exanthematous pustulosis: role of cytotoxic T-cells in pustule formation. Am J Pathology. 2002;161:207986.

12. Choquet-Kastylevsky G, Intrator L, Chenal C, Bocquet H, Revuz J, Roujeau JC. Increased levels of interleukin 5 are associated with the generation of eosinophilia in drug-induced hypersensitivity syndrome. Br J Dermatol. 1998;139:1026-32.

13. Mennicke M, Zawodniak A, Keller M, Wilkens L, Yawalkar N, Stickel F, et al. Fulminant liver failure after vancomycin in a sulfasalazine-induced DRESS syndrome: fatal recurrence after liver transplantation. Am J Transplant. 2009;9:2197-202.

14. Pichler WJ, Adam J, Watkins S, Wuillemin N, Yun J, Yerly D. Drug Hypersensitivity: How Drugs Stimulate $\mathrm{T}$ Cells via Pharmacological Interaction with Immune Receptors. Int Arch Allergy Immunol. 2015;168:13-24.

Cite this article as: Chularojanamontri L, Tuchinda P, Srinoulprasert Y, Kulthanan K, Pichler WJ. Sequential appearance of four clinical delayed drug hypersensitivity in the same patient. Int J Basic Clin Pharmacol 2016;5:2688-91. 